\title{
O Jornal Nacional e as estrafégias de sobrevivência econômica e política da Globo no contexto da ditadura militar
}

\section{RESUMO}

$\mathrm{O}$ artigo propõe analisar historicamente a relação de dependência/independência política e econômica da televisão brasileira, através de um estudo de caso, o da TV Globo e do seu principal telejornal, o Jornal Nacional, programa mais antigo em exibição na televisão brasileira. No ar desde $1^{\circ}$ de setembro de 1969, o Jornal Nacional pode ser compreendido como produto da articulação entre os interesses da elite política e econômica e os interesses políticos e econômicos dos militares que marcaram as décadas de 1960 e 1970, que é também o período de consolidação de um mercado cultural no Brasil. Argumentamos que a consolidação da televisão brasileira está associada ao governo militar (1964-1985), à Doutrina de Segurança Nacional e Desenvolvimento e à idéia de integração nacional e evidenciamos os movimentos políticos e econômicos fundamentais para a consolidação da TV Globo, entre eles a criação do seu padrão Globo de qualidade, uma composição de estratégias econômicas, comerciais, políticas, tecnológicas, produtivas e estéticas que evidencia que a Globo foi, no momento de consolidação da televisão no Brasil, a emissora que melhor percebeu as potencialidades do veículo e que melhor reuniu as condições econômicas e políticas para transformar a sua programação num objeto de consumo de massa.

\section{PALAVRAS-CHAVE}

Jornal Nacional

TV Globo

Ditadura Militar

\section{Itania Maria Mota Gomes}

Professora do Programa de Pós-Graduação em Comunicação e Cultura Contemporâneas da UFBA/BA/BR

itania@ufba.br
The Jornal Nacional and the survival strategies of economic and political the Globo in the context of the military dictatorship

\section{ABSTRACT}

The article proposes to examine the historical relationship of the political and economic dependency / independence of Brazilian television, through a case study, the Globo TV and its main newscast, Jornal Nacional, older program featured on Brazilian television. On the air since September 1, 1969, the National Journal can be understood as a product of the joint between the interests of political and economic elite and the political and economic interests of the military that marked the 1960s and 1970s, who is also the period consolidation of a cultural market in Brazil. We argue that the consolidation of Brazilian television is associated with the military government (1964-1985), the Doctrine of National Security and Development and the idea of national integration and noticed the political and economic movements fundamental to the consolidation of TV Globo, among them the creation their standard of quality Globo, a composition of economic strategies, commercial, political, technological, productive and aesthetic that demonstrates that the Globe was at the time of consolidation of television in Brazil, the broadcaster who best realized the potential of the vehicle and that best met the economic and political conditions to transform their program into an object of mass consumption.

\section{KEYWORDS}

Jornal Nacional

TV Globo

Military Dictatorship 
0 Jornal Nacional da Rede Globo de Televisão está no ar, de modo ininterrupto, há 40 anos, desde o dia $1^{\circ}$ de setembro de 1969 e representa o conjunto mais bem acabado de marcas que caracterizam um telejornal no Brasil. O JN é, atualmente, o telejornal mais popular do Brasil, personagem importante na história política, econômica e social do país. Ele tem o tempo publicitário mais caro da TV brasileira: uma publicidade de 30 segundos veiculada no Jornal Nacional custa 367 mil reais $^{1}$ e seus índices de audiência andam na casa dos $35 \%$, índice inferior apenas ao de outras duas produções da própria TV Globo, as telenovelas do horário noturno ${ }^{2}$.

Tomando seus quarenta anos como um pretexto, este artigo $^{3}$ analisa historicamente a relação de dependência/ independência política e econômica da televisão brasileira através de um estudo de caso, o da Rede Globo de Televisão e seu principal telejornal do horário nobre, nos anos iniciais de sua formação. Mostramos que o Jornal Nacional é produto da articulação entre os interesses da elite brasileira e do governo militar e os ideais de modernização e de integração nacional, articulação que implicará no desenvolvimento, por parte da TV Globo, de uma estratégia que significou submeter-se à Ideologia da Segurança Nacional e à censura ao mesmo tempo em que se transformava na principal emissora de televisão no Brasil. E evidenciamos que

\section{- padrão Globo de qualidade reúne elementos da ordem dos investimentos tecnológicos, da profissionalização do sistema de produç̃̃o televisivo, do sistema de comercialização e da qualidade estética de seus produtos sendo fundamental para garantir o sucesso do Jornal Nacional.}

O Jornal Nacional é hoje o programa mais antigo em exibição na televisão brasileira. Tendo estreado em primeiro de setembro de 1969, o programa inaugurou também o sistema de transmissão em rede, por microondas, no Brasil. Ele foi transmitido, simultaneamente, ao vivo, para seis capitais brasileiras: Rio de Janeiro, São Paulo, Belo horizonte, Curitiba, Porto Alegre e Brasília, atingindo 56 milhões de brasileiros. Era o maior sistema de transmissão em rede da América do Sul (Veja, 1969, p. 68).

Em sua primeira edição, o Jornal Nacional anuncia aquela que seria a sua marca mais forte. Segundo o site da emissora:

Hilton Gomes, ao lado de Cid Moreira, abriu a primeira edição do JN anunciando: "O Jornal Nacional, da Rede Globo, um serviço de notícias integrando o Brasil novo, inaugura-se neste momento: imagem e som de todo o país". Cid Moreira encerrou: "É o Brasil ao vivo aí na sua casa. Boa noite". ${ }^{4}$

O ideal de integração nacional estava na origem do novo programa e se tornou possível com a tecnologia de transmissão em rede. Fazer com que "56 milhões de brasileiros tenham mais coisas em comum. Além de um simples idioma", como dizia o anúncio $^{5}$ do novo programa nas principais publicações impressas do país, era ao mesmo tempo uma estratégia política e econômica: para Walter Clark Bueno, diretor geral da Globo na época, a transmissão em rede era a solução para a permanente crise vivida pela televisão brasileira (Borgerth, 2003, p. 39-53).

Segundo a biografia de Roberto Marinho, fundador da emissora, contudo, esse ideal de integração nacional e desenvolvimento é muito anterior à própria fundação da TV Globo. Segundo Pedro Bial, seu biógrafo, é possível enxergar na família Marinho uma linhagem de homens comprometidos com a modernização do Brasil e "fácil identificar em Roberto uma continuidade do projeto político e empresarial de Irineu" (Bial, 2004, p. 42). Para ele, Roberto Marinho herdou o ideal do pai, o jornalista carioca Irineu Marinho, fundador do jornal O Globo, do Rio de Janeiro. Comentando a atuação do jornalista-pai na imprensa carioca na década de 1910, época em que fundou o jornal vespertino $A$ Noite, Bial relaciona pai e filho:

Irineu Marinho bem sabia do desmando federativo, e esta consciência iria se expressar mais tarde em seu apoio a um projeto de 
unificação nacional, o movimento tenentista [...] Roberto Marinho nunca foi um ideológico, mas este ideal de integração da nação herdou-o do pai e levou-o além. Mesmo porque suas ambições de empreendedor dependiam disso (Bial, 2004, p. 56).

Até certo ponto, podemos dizer então, que o Jornal Nacional é produto da articulação entre os interesses da elite política e econômica e os interesses políticos e econômicos dos militares. Esta articulação se mostra mais evidente nos anos 1960 e 1970, que é também o período de consolidação de um mercado cultural no Brasil. A consolidação da televisão brasileira está associada ao governo militar (1964-1985), à Doutrina de Segurança Nacional e Desenvolvimento ${ }^{6}$ e à ideia de integração nacional. A Doutrina de Segurança Nacional e Desenvolvimento tinha como meta criar condições para a implantação de um modelo de desenvolvimento econômico extremamente favorável à entrada do capital estrangeiro, condições que eram interpretadas como sendo o fortalecimento do estado nacional, a implantação de uma infra-estrutura capaz de transformar o Brasil em uma potência econômica e o controle dos movimentos sociais.

[...] O Estado militar aprofunda medidas econômicas tomadas no governo Juscelino ${ }^{7}$, às quais os economistas se referem como 'a segunda revolução industrial' no Brasil. Certamente os militares não inventam o capitalismo, mas 64 é um dos momentos de reorganização da economia brasileira que cada vez mais se insere no processo de internacionalização do capital; o Estado autoritário permite consolidar no Brasil o 'capitalismo tardio'. Em termos culturais essa reorientação econômica traz consequências imediatas, pois, paralelamente ao crescimento do parque industrial e do mercado interno de bens materiais, fortalece-se o parque industrial de produção de cultura e o mercado de bens culturais (Ortiz, 1989, p. 114).

Em setembro de 1965 é criada a Empresa Brasileira de Telecomunicações (Embratel), que inicia uma política modernizadora para as telecomunicações. Já no seu primeiro ano de atuação, a estatal tornou-se sócia do Intelsat (Consórcio Internacional de Comunicações por Satélite), formado na época por 11 países, e logo em seguida começou a operar, via satélite, os serviços internacionais de telefonia, de telex e telegrafia e de canal para TV. A Embratel criou as condições para que o telefone e a televisão chegassem às regiões mais afastadas do país, e a conexão telefônica via satélite possibilitava uma integração mais ágil entre as diversas regiões brasileiras e entre o Brasil e o mundo. Pouco tempo depois da criação da Embratel, as emissoras de televisão puderam transmitir a chegada do homem à lua, em 1969, e a Copa do Mundo de Futebol, em 1970.

Em março de 1969, a Embratel inaugurou o Tronco Sul, que permitiu integrar, por uma rede terrestre de microondas, São Paulo, Rio de Janeiro, Curitiba e Porto Alegre. A rede era formada por repetidores posicionados a intervalos de quase $50 \mathrm{~km}$ de distância, que recebiam o sinal do equipamento anterior, amplificavam e o retransmitiam para o próximo. O primeiro produto a fazer uso pleno da tecnologia foi o Jornal Nacional, lançado em $1^{\circ}$ de setembro daquele ano. A Embratel concluiu em outubro de 1972 a implantação dos troncos do Sistema Nacional de Telecomunicações. Quando a Embratel foi criada, havia um sistema de microondas de pouco mais de Dois mil km de extensão, ligando São Paulo, Rio de Janeiro, Belo Horizonte e Brasília. Em 1972, eram mais de 11,5 mil $\mathrm{km}$ de rotas de microondas e 5,5 mil $\mathrm{km}$ de rotas de tropodifusão, interligando todas as capitais e as principais cidades do país (Cruz, 2009).

Foi esse sistema de microondas que permitiu a interligação de todo o território brasileiro e, mais especificamente, o funcionamento do sistema de rede, condição fundamental para a consolidação da TV no Brasil e para o lançamento do Jornal Nacional.

A infra-estrutura necessária ao desenvolvimento da TV é resultado, então, de um investimento do Estado que, guiado pela ideologia de Segurança Nacional e pelos esforços de integração nacional promove uma revolução tecnológica no sistema de telecomunicações. $\mathrm{O}$ investimento em telecomunicações e o interesse na integração nacional põem lado a lado os militares e os empresários, ainda que, como diz Renato Ortiz, "enquanto os militares propõem a unificação política das consciências, os empresários sublinham o lado 
da integração do mercado. O discurso dos grandes empreendedores da comunicação associa sempre a integração nacional ao desenvolvimento do mercado" (1989, p. 118). Assim,

\section{a própria noção de uma identidade culfural brasileira vai se redefinir e será reinferprefada em termos mercadológicos: é nacional aquilo que está infegrado ao mercado de consumo - inclusive e, sobrefudo, mercado de consumo de bens simbólicos.}

Nesses termos, e a partir da articulação entre interesses políticos e interesses econômicos, cultura nacional será identificada à cultura popular de massa.

Essa articulação de interesses criará uma dinâmica em que os empresários se submetem politicamente ao governo militar, enquanto que procuram consolidar sua independência econômica. Assim, no caso da TV Globo, a estratégia adotada foi a de se submeter à Ideologia da Segurança Nacional e à censura ao mesmo tempo em que se transformava na principal emissora de televisão no Brasil. Para que essa estratégia tivesse sucesso, era preciso estabelecer um pacto com os militares, através do qual a TV controlava a produção de conteúdos de seus programas em troca do apoio do governo para a construção da infra-estrutura necessária para a consolidação da indústria televisiva e apoio político para aprovação da legislação de seu interesse. Em 1973, por exemplo, a TV Globo e a TV Tupi assinam um protocolo de autocensura, pelo qual se comprometem a regular a produção de conteúdos para evitar a intervenção militar nas emissoras.

Em relação ao Jornal Nacional, a estratégia adotada foi enfatizar a qualidade técnica da produção e circulação em detrimento do conteúdo propriamente jornalístico. Em razão das restrições da censura, mas também em razão de uma concepção da função da televisão no Brasil, o Jornal Nacional optou por desenvolver-se e consolidar-se através de uma estratégia na qual qualidade e confiabilidade eram resultado do investimento tecnológico da emissora. Esse foi o modo como a TV Globo e seu jornalismo se desenvolveram - à ausência de liberdade de informação contrapôs-se o chamado padrão Globo de qualidade.

Muitos estudiosos da televisão têm rapidamente interpretado o "padrão Globo de qualidade" como ênfase na qualidade estética dos produtos televisivos da emissora. Mas isso é dizer muito pouco sobre uma estratégia ao mesmo tempo política e econômica. O padrão Globo de qualidade traduz-se, claro, pela qualidade estética de seus produtos, mas ele reúne elementos da ordem dos investimentos tecnológicos, da profissionalização do sistema de produção televisivo e do sistema de comercialização e implicou largamente a independência da TV das agências de publicidade e dos anunciantes. Para compreendermos melhor este processo, precisaremos voltar um pouco no tempo, ao início da história da televisão no Brasil.

A televisão, entre nós,
já́ nasce como televisão
comercial, privada, e se
consolida como principal
veículo de comunicação
através dos vários projetos
de modernização levados a
cabo pelas elifes brasileiras,
na configuração de um estado
nacional.
Em 18 de setembro de 1950 acontece a inauguração
da TV Tupi, de São Paulo, de Francisco de Assis
Chateaubriand Bandeira de Melo, que era dono do
grupo Diários Associados, o maior grupo de mídia do
país, naquele momento. Os Diários Associados eram
o grupo proprietário dos principais jornais, revistas
e emissoras de rádio. Era dos Diários Associados a
revista O Cruzeiro, principal revista ilustrada brasileira
no século XX. Em 22 de novembro do mesmo ano são
autorizadas as concessões da TV Record, da TV Tupi
do Rio de Janeiro e da TV Jornal do Comércio, do

A televisão, entre nós, iá nasce como felevisão comercial, privada, e se veliculo como principal veículo de comunicação afravés dos vários projetos cabo pelas elites brasileiras, na configuração de um estado nacional.

Em 18 de setembro de 1950 acontece a inauguração da TV Tupi, de São Paulo, de Francisco de Assis Chateaubriand Bandeira de Melo, que era dono do grupo Diários Associados, o maior grupo de mídia do país, naquele momento. Os Diários Associados eram o grupo proprietário dos principais jornais, revistas e emissoras de rádio. Era dos Diários Associados a revista $\mathrm{O}$ Cruzeiro, principal revista ilustrada brasileira autorizadas as concessões da TV Record, da TV Tupi do Rio de Janeiro e da TV Jornal do Comércio, do 
Recife. Em 1951, existem 7 mil aparelhos de TV no Rio e em São Paulo. Agências de publicidade, sobretudo a McCann Erikson e J.W. Thompson, as mais fortes, eram as responsáveis pela produção dos programas e pelas contratações de artistas e jornalistas.

Nesse período, eram os anunciantes que estabeleciam a programação televisiva. O tempo da TV era vendido por um preço sempre abaixo do custo efetivo, daí porque o anunciante não só financiava como viabilizava a produção. Isso fica absolutamente evidente pelos nomes dos programas: Teatro Good-Year, Telenovela Mappin, Recital Johnson, Ginkana Kibon, Repórter Esso. Mesmo os programas jornalísticos recebiam patrocínio - a exemplo do Repórter Esso, o telejornal de maior audiência à época. "Anunciantes e agências de publicidade não eram meros vendedores de produtos, mas também produtores de cultura" (Ortiz, 1989, p. 61). Como as emissoras não conseguiam arcar com os custos de produção, era impossível administrar o tempo e o valor comercial da publicidade.

Esse sistema só vai mudar no início dos anos 70, quando as agências começam a comprar os espaços televisivos, ao invés de patrocinar os programas. A experiência pioneira, nesse sentido, não foi da Globo, mas da TV Excelsior de São Paulo, que entrou no ar em julho de 1960 e foi a primeira emissora brasileira a padronizar sua programação horizontalmente e verticalmente. Implantando no Brasil a noção de grade televisiva, a TV Excelsior torna-se dentro de seis meses de operação, a líder de audiência na cidade de São Paulo ${ }^{8}$.

O padrão Globo de qualidade não pode ser compreendido sem o acordo inicial com o grupo TimeLife ${ }^{9}$ e sem as presenças de Joe Wallach, Walter Clark Bueno, José Bonifácio de Oliveira Sobrinho, o Boni, e Armando Nogueira, no comando do jornalismo, nos anos de consolidação da emissora. Em 1961, Roberto Marinho firma um contrato de assistência técnica com o grupo estadunidense Time-Life, segundo o qual a TV Globo ficaria responsável pela compra e instalação dos equipamentos e a Time-Life prestaria assessoria técnica para implantação da emissora - a TV Globo seria inaugurada em abril de 1965. Segundo Daniel Herz “a Time não assiste tecnicamente a TV Globo, mas de fato administra e gere todo seu patrimônio" (1987, p. 115).

O contrato previa participação da Time-Life nos lucros líquidos da TV Globo, o que era ilegal segundo o artigo 160 da Constituição brasileira de 1946 e a Lei No 4.117, de 27 de agosto de 1962 que institui o Código Brasileiro de Telecomunicações ${ }^{10}$. O artigo 160 da
Constituição de 1946 afirmava:

É vedada a propriedade de empresas jornalísticas, sejam políticas ou simplesmente noticiosas, assim como a de radiodifusão, a sociedades anônimas por ações ao portador e a estrangeiros. Nem esses, nem pessoas Jurídicas, excetuados os Partidos Políticos nacionais, poderão ser acionistas de sociedades anônimas proprietárias dessas empresas. A brasileiros [...] caberá, exclusivamente, a responsabilidade principal delas e a sua orientação intelectual e administrativa.. ${ }^{11}$

Logo depois da inauguração da TV Globo do Rio de Janeiro, os Diários Associados, grupo proprietário da Rede Tupi e também da revista O Cruzeiro, que tinha como principal concorrente na América Latina a revista Life, iniciaram uma campanha contra a presença de capital estrangeiro na mídia brasileira. João Calmon, deputado, diretor geral dos Diários Associados e presidente da Associação Brasileira de Empresas de Rádio e Televisão, e Carlos Lacerda, então governador da Guanabara, estado do Rio de Janeiro, denunciaram a existência de um acordo entre Roberto Marinho e o grupo Time-Life. Em outubro de 1965 o deputado Eurico de Oliveira apresentou um requerimento à Câmara dos Deputados pedindo a instauração de uma Comissão Parlamentar de Inquérito. A CPI durou quase um ano e terminou com um parecer desfavorável à Globo. Pouco tempo depois a TV Globo desfez o acordo com a Time-Life.

De todo modo, o acordo inicial com a Time-Life foi fundamental para a consolidação empresarial da emissora, em pelo menos três aspectos: assessoria técnica para implantação dos equipamentos e treinamento de pessoal, assessoria contábil e administrativa e montagem de uma equipe brasileira que constituiria o padrão Globo de qualidade. A presença de Joe Wallach ${ }^{12}$, empregado do grupo Time-Life na Globo era um dos principais motivos de desconfiança dos deputados durante a CPI, pois eles a consideraram uma evidência de que a empresa estadunidense estaria participando da orientação intelectual e administrativa da emissora. Wallach teve um papel fundamental na consolidação da TV e depois Rede Globo. No início, ele funcionava como uma espécie de assessor responsável pela contabilidade da Globo, mas seu papel foi muito mais amplo.

Ainda em 1971, Joe Wallach naturalizou-se brasileiro e chegou a renunciar à cidadania americana, até que o Brasil passou a permi- 
tir dupla cidadania. Com o fim do acordo com a Time-Life, tornou-se diretor executivo da TV Globo, posto que o levou a integrar o Conselho Executivo da emissora. Nesse período, trabalhou junto ao Boni, na época diretor de programação e produção da emissora, na implantação do sistema de transmissão das ondas de TV, o começo do modelo de rede [...] Wallach contribuiu, ainda, para a formação da Rede Globo através do programa de adesão das afiliadas espalhadas pelo país, e das Centrais Globo, núcleos como o de Jornalismo, o de Produção e o de Engenharia. Nesse mesmo período, assumiu o cargo de superintendente executivo da emissora. Ainda nos anos 1970, Wallach participou da expansão dos negócios da Rede Globo para o mercado internacional: iniciava-se a comercialização de novelas e séries para outros países ${ }^{13}$.

Joe Wallach deixou a Rede Globo em 1980, mas tornou-se consultor da Rede Globo na Telemontecarlo, originalmente uma subsidiária da emissora brasileira na Itália. De volta ao Brasil, em 1991, integrou o grupo responsável pala criação da Globosat, primeira programadora de TV por assinatura brasileira ${ }^{14}$.

Além de implantar um eficiente sistema de gestão financeira, "foi Wallach quem convenceu Roberto Marinho a dar a Walter Clark o cargo de diretor geral da TV Globo" ${ }^{15}$. Walter Clark já tinha uma experiência de quase 10 anos de televisão quando foi trabalhar na Globo. Ele havia trabalhado na Interamericana, uma das maiores agências de publicidade brasileiras na época, e, depois, na TV Rio. Tornou-se primeiro diretor comercial, responsável por reestruturar o setor comercial e por reformular a programação e, depois, diretor-geral da TV Globo, que até então apresentava modestos índices de audiência no Rio de Janeiro, ficando atrás da TV Rio, da TV Excelsior e da TV Tupi. A Globo começou a ganhar audiência em fevereiro de 1966, quando, por determinação de Walter Clark, a emissora interrompeu sua programação durante três dias para realizar a cobertura completa das enchentes que atingiam a cidade do Rio de Janeiro. Sobre a relação entre Walter Clark e Joe Wallach, Luiz Eduardo Borgerth, diretor administrativo da TV Globo de São Paulo à época, dirá: "Nunca se apurou quem tinha razão, se o Joe 'temos que gastar menos do que faturamos' ou se Walter 'temos que faturar mais do que gastamos', pois logo ficou impossível gastar mais do que se ganhava" (Borgerth, 2003, p. 77).

Walter Clark foi o principal responsável, na Globo, pela profissionalização dos sistemas de produção e de comercialização. Como diretor geral ele "começou a realizar o seu sonho de fazer da televisão uma atividade séria, profissional, sólida, técnica e, principalmente, respeitada; não mais comandada ao sabor dos interesses e gosto das agências de publicidade que até então 'traziam' o seu programa pronto ou o roteiro do que queriam [...]" (Borgerth, 2003, p. 44). Isso implicou a independência da produção de conteúdo da TV Globo das agências de publicidade e dos anunciantes. "Para Walter Clark, as televisões deveriam ser como os jornais, que faziam seu produto sem ouvir os anunciantes" (Borgerth, 2003, p. 45). Foi Walter Clark o responsável pela implantação de uma nova relação com as agências de publicidade e os anunciantes: a consolidação da programação da Globo possibilitou que a emissora passasse a vender o tempo nos intervalos comerciais da programação televisiva, e as agências passaram a comprar o tempo para seus anúncios, ao invés de patrocinar os programas. Para que isso fosse possível, no entanto, era fundamental assegurar boa programação e índices garantidos de audiência.

Walter Clark foi o responsável pela contratação - para o cargo de superintendente de produção e programação -, em março de 1967, de José Bonifácio de Oliveira Sobrinho, o Boni, com quem trabalhara na TV Rio e que o ajudaria a implantar o modelo de programação que levou a TV Globo ao posto de líder de audiência no país. Juntos, trouxeram para a emissora a noção de continuidade e foi deles a ideia de levar ao ar um programa jornalístico intercalando duas novelas, na faixa de programação considerada o horário nobre. Também foi obra dos executivos a estruturação do núcleo de novelas da TV Globo e a criação de diversos programas de grande sucesso, como o Fantástico (1973) e o Globo repórter (1973), entre outros ${ }^{16}$.

Walter Clark e José Bonifácio de Oliveira Sobrinho conceberam o formato de programação que a TV Globo adota até hoje, com a grade do horário nobre formada por três novelas, o Jornal Nacional entre a segunda e a terceira, e uma atração especial a seguir.

Boni promoveu também importantes mudanças 
na área artística da TV Globo. Foi ele quem concluiu ser imprescindível mudar os rumos da teledramaturgia da emissora, ainda presa ao dramalhão, ao perceber o filão que havia sido aberto com o sucesso da novela Beto Rockefeller, exibida em 1968 na TV Tupi, com direção de Walter Avancini e Lima Duarte. Com o aval de Walter Clark, Boni apostou em uma dramaturgia mais realista que retratava o cotidiano brasileiro contemporâneo, tendo sido responsável pela entrada de Daniel Filho, Dias Gomes e Janete Clair na Rede Globo. Em 1970, Boni passou a ser o superintendente de Produção e Programação da Rede Globo e era responsável por todas as áreas de programação da emissora, inclusive o jornalismo, que esteve sob a sua supervisão até 1995. Numa das decisões mais importantes para a consolidação do nível técnico, do faturamento e da audiência da TV Globo, Walter Clark passou para Boni também o comando operacional e o planejamento técnico da emissora, o que foi fundamental para racionalizar o uso da infra-estrutura técnica necessária à produção de conteúdo e à qualidade da programação da TV Globo. Em 1980, Roberto Irineu Marinho já ocupava a vice-presidência da Rede Globo e Boni assumiu a vice-presidência de operações da TV Globo, função que exerceu até 1997. Permaneceu como consultor da emissora até 2001, quando se afastou da Globo para criar TV Vanguarda, afiliada à TV Globo no interior de São Paulo.

No jornalismo, Armando Nogueira foi um dos principais responsáveis pela consolidação de um padrão de qualidade. Ele, que também entrou na TV Globo pelas mãos de Walter Clark - quando, em setembro de 1966, o programa esportivo Grande Resenha Facit, da TV Rio foi para a Globo carregando consigo todos os seus integrantes - criou e implantou o Jornal Nacional e o Globo Repórter. Entre outubro de 1966 e até 1990, Armando Nogueira esteve no controle do jornalismo, entre 66 e 74, na direção do departamento de Jornalismo da emissora, e, a partir de 1974, com as reestruturações internas da Globo, na chefia da Central Globo de Jornalismo, onde ficou até 1990. Na sequência do caso da edição que o Jornal Nacional fez do debate entre Fernando Collor de Mello e Luis Inácio Lula da Silva, no segundo turno das eleições presidenciais de 1989, afastou-se da Globo. Armando Nogueira morreu em 29 de março último.

Nos anos iniciais do Jornal Nacional, o padrão Globo de qualidade se traduziu por uma ênfase na qualidade técnica da produção em detrimento do conteúdo jornalístico, em razão dos limites impostos pela censura. Ainda que o governo do general Ernesto Geisel (1974-1979) tenha iniciado o período de distensão e de liberalização política da ditadura militar, só a partir do governo do general João Batista Figueiredo (19791985), é que o Departamento de Jornalismo não recebeu mais nenhuma ordem de censura. Segundo Armando Nogueira, no entanto, a censura permaneceu em forma de autocensura, praticada pelos próprios profissionais da TV Carvalho, 1979-1980).

Assim, qualidade e confiabilidade eram, no programa, o resultado do investimento da emissora na contratação dos melhores profissionais, na melhor tecnologia disponível e na transmissão em rede nacional, configuradora de uma identidade nacional brasileira. Desde esse período, podemos dizer que o Jornal Nacional se equilibra entre a quase perfeição técnica (de imagem) e um tom oficial ou institucional. Desde então,

a Globo manteve o hábito de oferecer um trafamento bastante generoso às auforidades governamentais ao mesmo tempo em que não abre mão de sua independência econômica, aquela que lhe garante poderio tecnológico, qualidade de seus produtos e, consequentemente, altos índices de audiência.

O padrão Globo de qualidade significa, então, uma composição de elementos - econômicos, comerciais, políticos, tecnológicos, produtivos, estéticos - que colocou a Globo em vantagem em relação às demais emissoras existentes no Brasil. Ele pode ser interpretado como a melhor evidência de que a Globo foi, no momento de consolidação da televisão no Brasil, a emissora que melhor percebeu as potencialidades do veículo e que melhor reuniu as condições econômicas e políticas para transformar a sua programação num objeto de consumo de massa. Se, hoje, o padrão Globo de qualidade dá 
personalidade à programação da emissora e tornou a TV Globo uma das principais marcas no mercado midiático mundial, naquele momento ele foi o responsável pela sobrevivência econômica e política da emissora.

\section{REFERÊNCIAS}

ALVES, Maria Helena Moreira. Estado e Oposição no Brasil (1964-1984). Petrópolis: Vozes, 1984.

BONNER, William. Jornal Nacional: modo de fazer. Rio de Janeiro: Globo, 2009.

BORGERTH, Luiz Eduardo. Quem e como fizemos a TV Globo. São Paulo: A Girafa, 2003.

CARVALHO, Elizabeth. Telejornalismo, a década da tranquilidade. In: KEHL, Maria Rita; RIBEIRO, Santuza Naves, CARVALHO, Elizabeth. Anos 70: Televisão. Rio de Janeiro: Europa, 1980.

CRUZ, Renato. A TV Globo e a Embratel. In: O Estado de São Paulo. Disponível em: <http://www.estadao. com.br/tvdigital/globoembratel.shtm>. Acesso em 15 jul. 2009.

HERZ, Daniel. A bistória secreta da Rede Globo. Porto Alegre: Tchê, 1987.

REZENDE, Guilherme Jorge. Telejornalismo no Brasil: um perfil editorial. São Paulo: Summus, 2000.

ORTIZ, Renato. A moderna tradição brasileira. Cultura brasileira e indústria cultural. 2 ed, São Paulo: Brasiliense, 1989.

MEMÓRIA GLOBO. Jornal Nacional: a notícia faz história. Rio de Janeiro: Jorge Zahar, 2004.

MOYA, Álvaro. Glória In Excelsior. Ascensão, apogeu e queda do maior sucesso da televisão brasileira. São Paulo: Imprensa Oficial do Estado de São Paulo, 2004.

VEJA. O país numa rede. Revista VEJA, ed. 62, 3 set. 1969, p. 68. Disponível em <http:// veja.abril.com.br/ acervodigital $>$.

CAPARELLI, Sérgio; SANTOS, Suzy. O setor audiovisual brasileiro: entre o local le o internacional.
EPTIC - Revista de Economía Política de las Tecnologías de la Información y Comunicación, v. VII, n. 1, Ene. 2005.

JAMBEIRO, Othon. Raízes históricas da regulamentação de TV no Brasil. In: Textos de Cultura e Comunicação, n. 35, Salvador: Facom/UFBA, 1996.

JAMBEIRO, Othon. A regulação da TV no Brasil: 75 anos depois, o que temos? Estudos de Sociologia, v. 3, n. 24, p. 85-104, 2008.

\section{NOTAS}

${ }^{1} \mathrm{Na}$ telenovela das $21 \mathrm{~h}$, que tem mais audiência, uma inserção semelhante sai por 365 mil reais.

2 Segundo dados do Ibope, em http://www. almanaqueibope.com.br

${ }^{3}$ Uma versão preliminar deste artigo foi apresentada no VIII Lusocom, em Lisboa/Portugal, abril de 2009.

4 Do site do programa: http://jornalnacional.globo. com/Telejornais/0,GEN971-10405,00.html. Hilton Gomes apresentou o programa até 1972 e Cid Moreira permaneceu na função por 27 anos, até 1996, quando foi substituído por William Bonner, atual apresentador e editor-chefe do telejornal.

${ }^{5}$ Ver em Veja, 1969, a reprodução do anúncio.

${ }^{6}$ A Doutrina de Segurança Nacional e Desenvolvimento está associada a teorias geopolíticas, ao antimarxismo e às tendências conservadoras do pensamento social católico e prevê uma relação estreita entre desenvolvimento econômico e segurança interna e externa. No contexto brasileiro, ela surge como resposta ao crescimento dos movimentos sociais da classe trabalhadora - daí sua ênfase na ameaça de subversão interna e na guerra revolucionária. A DSND representa a consolidação da ideologia de segurança nacional, transplantada para o Brasil após a $2^{\mathrm{a}}$ Guerra Mundial, quando vários militares brasileiros de alta patente foram treinados no National War College, nos Estados Unidos. Seu objetivo principal era garantir metas de segurança para implantar uma geopolítica para todo o Cone Sul do Continente Americano, capaz de bloquear o perigo expansionista do comunismo internacional. Na perspectiva da DSND, não pode haver segurança nacional sem um alto grau de desenvolvimento econômico. O principal ideólogo da DSND foi o general Golbery do Couto e Silva. Ver Alves (1984).

${ }^{7}$ Juscelino Kubitschek foi presidente do Brasil entre 1956 e 1961, período no qual desenvolveu o Plano Nacional de 
Desenvolvimento, caracterizado pelo lema Cinqüenta anos em cinco. Seu Plano de Metas organizava-se em torno de seis grandes áreas: energia, transportes, alimentação, indústria de base, educação e a construção de uma nova capital para o Brasil, Brasília. Sua plataforma desenvolvimentista incluía a abertura da economia brasileira ao capital estrangeiro, a implantação da indústria automobilística, da indústria naval, a expansão da indústria pesada, a construção de usinas siderúrgicas e de grande usinas hidrelétricas, como Furnas e Três Marias, a construção de rodovias transregionais e o aumento da produção de petróleo da Petrobrás. No governo do General Ernesto Geisel, os militares lançam o II Plano Nacional de Desenvolvimento (1975-1979).

${ }^{8}$ Em 1963 a TV Excelsior lançou um dos principais telejornais brasileiros, o Jornal de Vanguarda, que ganhou o Prêmio Ondas, concedido pela Sociedad Española de Radiodifusion S.A, membro efetivo da Union Européenne de Radio-Télévision, que organizou os Prêmios Ondas de Radio e Televisão a partir de 1954, como o melhor telejornal do mundo. Em 1968 o programa sai do ar, em razão da edição do Ato Institucional $\mathrm{n}^{\circ} 5$, o mais abrangente e autoritário ato editado pela ditadura, que suspendeu direitos políticos no Brasil. A Excelsior é fechada, em dezembro de 1970, na sequência de uma série de problemas com o Governo Militar. Para uma história da TV Excelsior, ver Moya (2004).

9 A Time Life é uma das mais importantes produtoras e distribuidoras de livros, música, vídeos, dvds e produtos multimídia. Ela foi fundada em 1961 como uma divisão da Time Inc., especializada em livros. Seu nome tem origem nas duas principais revistas dos anos 60, a Time e a Life. Em 2003, a Time Life foi adquirida por Ripplewood Holdings L.L.C. e ZelnickMedia Corporation para tornar-se parte da Direct Holdings Worldwide L.L.C. Ver www.timelife.com.

${ }^{10}$ No Brasil, somente a Emenda Constitucional No 36, de 28 de maio de 2002 (http://www.planalto.gov.br/ ccivil_03/constituicao/emendas/emc/emc36.htm) abre a possibilidade de participação do capital estrangeiro na mídia brasileira, o que será regulado pela Lei $\mathrm{N}^{\mathrm{o}} 10.610$, de 20 de dezembro de 2002 (http://www.planalto.gov. br/CCIVIL/LEIS/2002/L10610.htm), que dispõe sobre a participação de capital estrangeiro nas empresas jornalísticas e de radiodifusão sonora e de sons e imagens. Estrangeiros e brasileiros naturalizados há menos de dez anos podem deter até 30\% do capital votante e do capital total das empresas jornalísticas e de radiodifusão, assegurados aos brasileiros natos e naturalizados há mais de dez anos o controle e a elaboração da programação, da linha editorial e do conteúdo jornalístico. Essas alterações na legislação brasileira são decorrência da assinatura do General Agreement on Trade in Services (GATS), que regulamenta, no âmbito da Organização Mundial do Comércio, todas as formas de prestação de serviços realizadas pelo comércio internacional. Ele foi aprovado em 15 de fevereiro de 1997 e implica o compromisso dos estados-membro da OMC em liberalizar seus serviços básicos de telecomunicações, ou seja, abrir o setor à participação do capital estrangeiro. No Brasil, que é membro da OMC desde $1^{\circ}$ de janeiro de 1995 , o marco regulatório inicial foi a emenda constitucional $\mathrm{n}^{\circ} .8$, promulgada em agosto de 1995 e transformada na Lei Geral das Telecomunicações - Lei no . 9.472/978, de julho de 1997, que revogou o antigo Código Brasileiro de Telecomunicações. A LGT não só autoriza a exploração dos serviços de telecomunicação pela iniciativa privada, como estabelece a criação de um órgão regulador para o setor, que virá a ser a Agência Nacional de Telecomunicações. A regulamentação neoliberal dos anos 90 enfatizou, em todos os setores, a abertura do mercado nacional ao capital estrangeiro, considerada uma via fundamental para o desenvolvimento do país. A transferência dos serviços prestados por empresas estatais ao controle privado e a abertura do mercado nacional ao capital estrangeiro foram a via política construída para a modernização do país sob o Governo Collor e em consonância com as diretrizes econômicas do Banco Mundial e do Fundo Monetário Internacional. Sobre a regulação das comunicações no Brasil, ver Jambeiro (1996; 2008); Caparelli \& Santos (2005), Bolaño (2003).

${ }^{11}$ A íntegra da constituição pode ser consultada em www. planalto.gov.br/ccivil_03/Constituicao/Constituiçao46. htm

${ }^{12}$ Ver em http://memoriaglobo.globo.com/Memoriag lobo/0,27723,GYP0-5271-269233,00.html um perfil de Joe Wallach.

13 Memória Globo: http://memoriaglobo.globo.com/ Memoriaglobo/0,27723,GYP0-5271-269233,00.html, Acesso em: 09 mar. 2010.

14 A Globosat surgiu em 1991, a partir da reunião de quatro canais de TV por assinatura, o Telecine, o GNT, o Multishow e o Top Sports (hoje SporTV). No início, a empresa era produtora de conteúdo e também distribuidora. Em 1993 as Organizações Globo criaram a Net Brasil, empresa destinada apenas às atividades de venda, distribuição e prestação de serviço na área de TV por assinatura. A Globosat tornou-se uma empresa exclusivamente voltada para a programação e a geração 
de conteúdo. Além dos quatro canais iniciais, hoje a Globosat possui também a Globo News, um canal de notícias 24 horas, o Universal Channel, o Shoptime, o Canal Brasil e o conjunto Telecine, que virou uma rede com cinco canais de diferentes gêneros de filmes, além de operar por pay per view. Além da distribuição por cabo, desde 1996 a empresa opera também o sistema Sky, que distribui o sinal digital diretamente do satélite para miniparabólicas instaladas nos domicílios dos assinantes. Hoje a Globosat é líder no mercado de TV por assinatura no Brasil. A Globosat saltou de 350 funcionários e quatro canais, em 1994, para 24 canais e mais de 1.000 funcionários, em 2008. São 16,5 milhões de telespectadores distribuídos por mais de 4,8 milhões de domicílios-assinantes. É a programadora de maior alcance médio diário: 6,1 milhões de telespectadores diferentes, em dados de janeiro a abril de 2009. Em dados atuais, dentre as 100 exibições de maior audiência da TV por Assinatura no primeiro semestre de 2009, 93 são da Globosat e cerca de 56\% do tempo médio dedicado pelo público à TV por assinatura no horário nobre estão distribuídos entre os Canais Globosat. Ver http://globosatcomercial.globo.com

15 Memória Globo: http://memoriaglobo.globo.com/ Memoriaglobo/0,27723,GYP0-5271-269233,00.html. Acesso em: 09 mar. 2010.

16 Memória Globo: http://memoriaglobo.globo.com/ Memoriaglobo/0,27723,GYP0-5271-256116,00.html. Acesso em: 09 mar. 2010. 